International Journal of Forensic Science \& Pathology (IJFP)

ISSN 2332-287X

\title{
A Study Of Cause of Death Certificates In India
}

Rao D*, S.Mukerjee, S. Ruia

Case Report

Associate Prof, i/c Head.Department of Forensic Medicine, Sapthagiri Institute of Medical Sciences and Research center, No 15,Chikkasandra, Hesargatta MainRoad, Bangalore, India.

\section{Abstract}

In the present study a total of 890 Cause of Death Certificates were examined Retrospectively from Eight different Centers during the period 2008-2013, of which 258 were retrieved from Hospital records and 632 from the Autopsy records, were examined for appropriateness of completion and the ability to construct a logical cause of death cascade. None of the Autopsy reports had a provision for the Standard Cause of Death recordings. Though Medico Legal Autopsy Contributed to only $15 \%$ of the minimal standards and rest $75 \%$ deviated from the accepted Standards and concluded with Mechanism or Mode of Death. Similarly in Hospital death cases 30.4\% satisfied minimal Standards and $69.8 \%$ of it were inappropriate in its completion and deviated from the Standards. The Demographic characters were inadequate in $72 \%$ of the Certificates. Only $14 \%$ of the Cause of Death statement after Medico Legal Autopsy were satisfying the ICD 10 Codes [2] and 98\% of the certificates lacks information on Contributing factors responsible for the Death and none of the Certificates had information about the Time interval between the Sequence of Events leading to death. Similarly Only 19\% of the Cause of Death statement in Hospital deaths were satisfying the ICD 10 Codes[2] and none of the certificates lacks information on Contributing factors and the Time interval between the Sequence of Events leading to death. The Autopsy information in the Certificate were also found to be incomplete as only 1\% indicated the place of Autopsy and only $36 \%$ informed the Date and time of Autopsy. Even the maternal death information was inadequate, with only $42 \%$ of the certificates informing the same. The Certificate Authors information was also inadequate with only $35 \%$ of the Certificates had information about the Designation, and Qualification and bore the Stamp.

\section{*Corresponding Author:}

Dr.Dinesh Rao,

Associate Prof, i/c Head.Department of Forensic Medicine,

Sapthagiri Institute of Medical Sciences and Research center,

No 15,Chikkasandra, Hesargatta MainRoad, Bangalore, India.

Tel: +91- 9741360206.

E-mail: dineshrao22@yahoo.com

Received: March 22, 2014

Accepted: February 18, 2014

Published: February 20, 2014

Citation: Rao D, S.Mukerjee, S. Ruia (2014) A Study of Cause of Death Certificates in India. Int J Forensic Sci Pathol. 2(2), 16-18. doi: http:// dx.doi.org/10.19070/2332-287X-140006

Copyright: Rao $\mathbf{D}^{\circ}$ 2014. This is an open-access article distributed under the terms of the Creative Commons Attribution License, which permits unrestricted use, distribution and reproduction in any medium, provided the original author and source are credited.

\section{Introduction}

Cause of Death Certificate though, a compulsory obligation on the part of Registered Medical Practioner [1], it is poorly performed and the information available in the Certificates are Inadequate, Inappropriate and Misleading the Health Policy Makers. The terminologies used in the Cause of Death statement should satisfy the ICD 10[2] coding and the Demographic Characters, Autopsy information and Authors information should all be adequate for a complete Cause of Death certificate. The information thus produced for the Registration is vital for the Statistical point of view for a Nation [3]. It is only based on this Statistics the Health planning, Health policies and Research are facilated. In the absence of Appropriate statistics the Money spent on this Health planning, Research and Disease prevention is mere waste of resources. Hence this study is undertaken to highlight the Inadequa- cies and inappropriateness of the Cause of Death certification.

\section{Material and Methods}

A total of 890 Cause of Death Certificates were retrieved from the Medical record department of the Concerned Centers, of which 258 were related to Hospital Deaths and 632 were from Autopsy records. The certificates thus retrieved were analysed and details recorded in the Standard proforma ANNEXURE -I.

They are than analyzed with standard Cause of Death Certificate as per International Criteria.

\section{Observations}

Table no 1, indicates the total no of Hospital and Autopsy certificates studied.

Table 1. Medical Certification of Cause of Death for the period of 2008-2013.

\begin{tabular}{|l|l|}
\hline $\begin{array}{l}\text { Total No of Medical } \\
\text { Certification }\end{array}$ & Cause of Death \\
\hline 258 & Hospital Death \\
\hline 632 & $\begin{array}{l}\text { Post Mortem Examination } \\
\text { Inquest }\end{array}$ \\
\hline 890 & Total \\
\hline
\end{tabular}

Table no 2, the Study of Hospital death certificates which indicates only $30.4 \%$ (n-14) of the certificates satisfied minimal standards and $69.6 \%$ of the certificates the information present were inappropriate and inadequate.

Autopsy Report of 890 cases: None of the provision for the cause of death statement as per W.H.O 
Table no 3, the Study of Medico Legal Autopsy death certificates which indicates only $15 \%$ (n-69) of the certificates satisfied minimal standards and $85 \%$ of the certificates the information present were inappropriate and inadequate. None of the Autopsy reports had a provision for the same.

Table No 2. Percentage of COD Reports (Hospital Deaths) meeting minimum Standards.

\begin{tabular}{|l|l|l|}
\hline Hospital Death & Percentage & Remark \\
\hline 78 cases & $30.4 \%$ & Minimal standard \\
\hline 180 cases & $69.6 \%$ & $\begin{array}{l}\text { Inappropriate/Mode of } \\
\text { Death } \\
\text { Mechanism of Death }\end{array}$ \\
\hline 258 cases & Total & \\
\hline
\end{tabular}

Table No 3. Percentage of COD Reports (Autopsy) meeting minimum Standards.

\begin{tabular}{|l|l|l|}
\hline No. of cases & $\begin{array}{l}\text { Percent- } \\
\text { age }\end{array}$ & Remark \\
\hline 95 & $15 \%$ & Showed Minimal Standard \\
\hline 537 & $85 \%$ & $\begin{array}{l}\text { Showed Mechanism of Death/ } \\
\text { Mode of Death }\end{array}$ \\
\hline 632 & Total & \\
\hline
\end{tabular}

Table no 4, showed the percentage of COD reports meeting Demographic details. Only $82 \%$ had adequate information on Name, Age and Sex Characters, 18\% lacked information on Sex or Age. But all the certificates did bear the name of the deceased. Only $42 \%$ certificates showed adequate information on Marital status, occupation and Date of Birth (DOB), 10\% of the certificates had no information of the same. $72 \%$ of the Certificates had inadequate Address, Time, place and date of Death information and $12 \%$ had no information for the same.

Table No 4. Percentage of COD Reports meeting Demographic Details.

\begin{tabular}{|l|l|l|l|l|}
\hline $\begin{array}{l}\text { Demographic } \\
\text { Characters }\end{array}$ & Adequate & $\begin{array}{l}\text { In } \\
\text { adequate }\end{array}$ & $\begin{array}{l}\text { Not } \\
\text { available }\end{array}$ & $\begin{array}{l}\text { Wrong } \\
\text { informa- } \\
\text { tion }\end{array}$ \\
\hline Name, Age, Sex & $82 \%$ & $18 \%$ & --- & --- \\
\hline $\begin{array}{l}\text { Marital Status/ } \\
\text { Occupation/ } \\
\text { DOB }\end{array}$ & $42 \%$ & $48 \%$ & $10 \%$ & --- \\
\hline $\begin{array}{l}\text { Address /Time, } \\
\text { Place and Date } \\
\text { of Death }\end{array}$ & $12 \%$ & $72 \%$ & $12 \%$ & ------ \\
\hline
\end{tabular}

Table no 5.Cause of Death Statement after Autopsy. Of the 632 (14\%) certificates only 90cases satisfied ICD 10 coding, most of them related to Asphyxia and Trauma. In $98 \%$ of the Certificates lacked information on the contributing factors and $83 \%$ showed inappropriate Underlying cause of death statement. None of the certificates had information on the time interval between the sequences of events leading to death.

Table no 6.Cause of Death Statement in Hospital Death.. Of the $258(19 \%)$ certificates only 49cases satisfied ICD 10 coding. In $76 \%$ of the Certificates lacked information on the Underlying cause of death. None of the certificates had information on the Contributing factors of Death and time interval between the sequences of events leading to death.

Table No 7. Percentage of COD Reports with Autopsy record Information All the certificates did contain Postmortem number but only $1 \%$ had information on place of Death, and 36\% had information on Date and time of Autopsy. Of the total certificates only $42 \%$ certificates had adequate information on Maternal Deaths.

Table No 7. Percentage of COD Recordings in Autopsy reports.

\begin{tabular}{|l|l|l|}
\hline COD-Autopsy Information & $\begin{array}{l}\text { Adequate } \\
\text { information }\end{array}$ & No information \\
\hline PM no & $100 \%$ & ---------- \\
\hline Date and Time of Autopsy & $36 \%$ & $64 \%$ \\
\hline Place of Autopsy & $1 \%$ & $99 \%$ \\
\hline $\begin{array}{l}\text { Maternal Deaths-Pregnancy } \\
\text { period. }\end{array}$ & $42 \%$ & $58 \%$ \\
\hline
\end{tabular}

Table No 8. Percentage of COD Reports with Authors Information. All the certificates bore the Signature of the Author, only $35 \%$ had information on the designation with Qualification of the Author similar percentage had Stamp on the certificates.

Table No 8. Percentage of COD Reports with Authors Information.

\begin{tabular}{|l|l|l|}
\hline COD-Autopsy Information & $\begin{array}{l}\text { Adequate } \\
\text { information }\end{array}$ & No information \\
\hline Name and Signature & $100 \%$ & ------------ \\
\hline $\begin{array}{l}\text { Designation with qualifica- } \\
\text { tions }\end{array}$ & $35 \%$ & $65 \%$ \\
\hline Stamp & $35 \%$ & $65 \%$ \\
\hline
\end{tabular}

\section{Discussion}

Cause of Death certification, though a compulsory obligation on the part of the Doctors [1], continues to be poorly performed despite and increased education at an undergraduate level. The Certification is done by the Treating Doctor or the Doctor who performs the Autopsy. Irrespective of the source and the Author of the certificate the Standards which needs to be adopted is uniform throughout the world. This standard format is approved by the WHO and the Terminology of the Diseases /Lesion entered

\section{Table No 5. COD Recordings after Autopsy}

\begin{tabular}{|l|l|l|l|l|}
\hline COD & Adequate information & No information & Wrong information & Information as per ICD-10 \\
\hline I a. Immediate Causes & $12 \%$ & $88 \%$ & $82 \%$ & $14 \%$ \\
\hline I b. Antecedent Causes & $05 \%$ & $95 \%$ & $46 \%$ & \\
\hline I c. Underlying Causes & $17 \%$ & $83 \%$ & $32 \%$ & \\
\hline II Contributing Factors & $02 \%$ & $98 \%$ & $86 \%$ & \\
\hline Time interval between each causes & Nil & $100 \%$ & ------------- & \\
\hline
\end{tabular}


Table No 6. COD Reporting Standards in Hospital Deaths.

\begin{tabular}{|c|c|c|c|c|}
\hline COD & Adequate information & No information & Wrong information & Information as per ICD-10 \\
\hline I a. Immediate Causes & $87 \%$ & $13 \%$ & $65 \%$ & $19 \%$ \\
\hline I b. Antecedent Causes & $06 \%$ & $94 \%$ & -------- & \\
\hline I c. Underlying Causes & $24 \%$ & $76 \%$ & $38 \%$ & \\
\hline II Contributing Factors & Nil & $100 \%$ & $==========$ & -------------- \\
\hline Time interval between each causes & Nil & $100 \%$ & 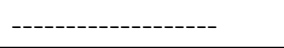 & --------------- \\
\hline
\end{tabular}

in the Format should satisfy the ICD 10[2] coding to facilitate the very purpose of issuing the Certificate. It has been observed that majority of certification in India don't satisfy the International standards and many have inadequate Demographic details. In the present study of the 690 certificates studied 258 certificates were from Hospital death records and 632 certificates were from Autopsy records. Of the 258 Hospital death certificates only $30.4 \%$ of the certificates were of minimum standards though adequate terminologies used to satisfy ICD10 coding few errors and omissions were present pertaining to Demography, Autopsy and Authors information this is in close observation to similar study conducted by Swift B, West K. [4] and Horner JS, Horner JW[5]. where $54 \%$ had minimal standards and $10 \%$ completed to a poor standard and only $41 \%$ had acceptable standards[5] which is in sharp contrast to the present study and that of wherein $69.6 \%$ certificates showed inappropriate or inadequate information. Of the 632 Autopsy death records only $15 \%$ of the recordings were of minimum standards though adequate terminologies used to satisfy ICD10 coding few errors and omissions were present pertaining to Demography, Autopsy and Authors information this is in sharp contrast to observations made by Fernando R. [6] and Cina SJ, et al [7] in a similar study where $38 \%$ and $37 \%$ of the Autopsy reports had recordings as per the internationally accepted criteria. 19\%[6] and 63\% had unacceptable causes of death which is in sharp contrast in the present study wherein $85 \%$ ( $n-537)$ of the Recordings the causes of death were unacceptable. In a study conducted by Slater DN[8] the unacceptable inaccuracies were found only in $5.4 \%$ of the Certificates. In the present study most of the unacceptable recordings in the Cause of death were considered due to information as to Mechanism of death or no antecedent cause or underlying cause and no contributing factors information and if the recordings existed they did not match ICD10 criteria. In the present study none of the Certificates or recordings showed the Time interval between the sequence of events causing the Death, which is in sharp contrast to a similar study conducted by Shantibala K et al[9] wherein, 65.3\% showed absence of time intervals. The demographic details form an important part of the certificate, because this gives the identity to the group or the individual, any error in this information is unacceptable in the present study $18 \%$ had inaccurate information, $72 \%$ of the Certificates had inadequate Address, Time, place and date of Death information and $12 \%$ had no information for the same. This information is essential for all Legal reason and to avoid speculations, The inadequate Authors information always raises the suspicion levels and encourages fraud besides making it difficult to identity the Author of the Certificate. Therefore, It is essential that the information on the certificate is accurate. It is used to compile statistics about death. These are needed for monitoring public health, planning and research, and so for improving the health of the population. Information from the certificate will be included in a register of deaths open to public scrutiny. Hence it is obvious that consequences of Inaccurate and inappropriate information in the Cause of Death recordings will prove disaster to the basic Health Care, Research and Disease prevention programs besides loss of Thousands of crores. Hence the present study stresses the importance of Educational intervention to improve the accuracy of Certification, similar were the views of Villar J, Pérez-Méndez L.[10] and Selinger CP et al [11]. Though incorporated in the undergraduate Curriculum other methods of training like Seminars, CME and if possible appropriate fines imposed on the Author for Inaccurate information or other suggestions like rejection of the certificate or recordings if it doesn't adhere to the minimum criteria should also be considered.

\section{References}

[1]. Section 10 (3) of the act read with rule 7 of the Karnataka Registration of Births and Deaths Rules, 1999

[2]. ICD 10 CODES

[3]. The registration of births and deaths (amendment) bill, 2012.

[4]. Swift B, West K. Death certification: an audit of practice entering the 21st century. Clin Pathol. 2002 Apr;55(4):275-9.

[5]. Horner JS, Horner JW J R Soc Med. 1998 Jul;91(7):371-6. Do doctors read forms? A one-year audit of medical certificates submitted to a crematorium.

[6]. Fernando R. Ceylon Med J. 1990 Jun;35(2):71-4. Medical certification of cause of death in the General Hospital, Colombo.

[7]. Cina SJ et al. Mil Med. 1999 Dec;164(12):897-9. Accuracy of death certification in two tertiary care military hospitals.

[8]. Slater DN. J Clin Pathol. 1993 Mar;46(3):232-4. Certifying the cause of death: an audit of wording inaccuracies.

[9]. Shantibala K et al. Indian J Public Health. 2009 Jan-Mar;53(1):31-3. Death certification in a teaching hospital--a one year review.

[10]. Villar J, Pérez-Méndez L BMC Health Serv Res. 2007 Nov 15;7:183. Evaluating an educational intervention to improve the accuracy of death certification among trainees from various specialties.

[11]. Selinger CP, Ellis RA, Harrington MG. CMAJ. 1998 May 19;158(10):1317-23. A good death certificate: improved performance by simple educational measures. 